\title{
FONTES E DOSES DE POTÁSSIO NA PRODUÇÃO E QUALIDADE DO GRÃO DE CAFÉ BENEFICIADO'1
}

\author{
ENILSON DE BARROS SILVA², FRANCISCO DIAS NOGUEIRA, PAULO TÁCITO GONTIJO GUIMARÃES ${ }^{3}$, \\ SILVIO JÚLIO DE REZENDE CHAGAS ${ }^{4}$ e LAERTE COSTA ${ }^{5}$
}

\begin{abstract}
RESUMO - Um experimento de campo foi instalado num Latossolo Roxo distrófico, localizado na Fazenda Experimental da EPAMIG, São Sebastião do Paraíso, MG, em fevereiro de 1993, utilizandose a espécie Coffea arabica L., cultivar Catuaí Vermelho, linhagem LCH 2077-2-5-44, para estudar o efeito de fontes e doses de $\mathrm{K}$ na produção e qualidade do grão de café beneficiado. Foi utilizado delineamento experimental em blocos casualizados, com quatro repetições, em esquema de parcelas subdivididas, utilizando-se três fontes de $\mathrm{K}$ nas parcelas $\left(\mathrm{KCl}, \mathrm{K}_{2} \mathrm{SO}_{4}\right.$ e $\left.\mathrm{K}_{2} \mathrm{SO}_{4} \cdot 2 \mathrm{MgSO}_{4}\right)$ e quatro doses nas subparcelas $\left(0,100,200 \mathrm{e} 400 \mathrm{~g} \mathrm{cova}^{-1} \mathrm{de} \mathrm{K}\right)$. Foi conduzido até outubro de 1994, tendo sido avaliados em 1993 e 1994, a produção, as variáveis qualitativas dos grãos beneficiados e os teores de K, $\mathrm{Mg}, \mathrm{S}$ e Cl nas folhas e grãos. Não existe resposta de produção, em dois anos, às fontes e doses de K. Nas variáveis qualitativas dos grãos verificou-se maior atividade da polifenoloxidase e menor acidez titulável total, em 1993, com o $\mathrm{K}_{2} \mathrm{SO}_{4}$. Em 1994, houve a mesma tendência quanto à atividade da polifenoloxidase e acidez titulável total, apresentando maior índice de coloração e resposta favorável ao incremento dos teores de açúcar total. $\mathrm{O} \mathrm{K}_{2} \mathrm{SO}_{4}$ promove melhor qualidade do grão de café beneficiado.
\end{abstract}

Termos para indexação: polifenoloxidase, índice de coloração, acidez titulável total, sulfato, açúcares.

\section{SOURCES AND DOSES OF POTASSIUM ON THE YIELD AND QUALITY OF GREEN COFFEE}

\begin{abstract}
A field experiment was established on a dystrophic Dusky Red Latosol of the EPAMIG experimental farm at São Sebastião do Paraíso, MG, Brazil, in February 1993, with coffee (Coffea arabica L.) cultivar Catuaí Vermelho, line LCH 2077-2-5-44, to study the effect of sources and doses of $\mathrm{K}$ on the yield and quality of green coffee. A randomized block experimental design with four replications was utilized, under a split-plot scheme, using three sources of $\mathrm{K}$ in the plots $\left(\mathrm{KCl}, \mathrm{K}_{2} \mathrm{SO}_{4}\right.$ and $\left.\mathrm{K}_{2} \mathrm{SO}_{4} \cdot 2 \mathrm{MgSO}_{4}\right)$ and four doses in the subplots $\left(0,100,200 \mathrm{e} 400 \mathrm{~g}\right.$ hole ${ }^{-1}$ of $\left.\mathrm{K}\right)$. The experiment was conducted till October 1994. In 1993 and 1994 the yield, the qualitative variables of the processed grains and the contents of $\mathrm{K}, \mathrm{Mg}, \mathrm{S}$ and $\mathrm{Cl}$ in the leaves and grains were evaluated. There was no response of yield along two years to the sources and doses of $\mathrm{K}$. For the processed grains, $\mathrm{K}_{2} \mathrm{SO}_{4}$ increased polyphenoloxidase activity and decreased total titrable acidity in the year 1993. In 1994, the same trend to polyphenoloxidase activity and total titrable acidity was observed, showing an even higher color index and favorable response in the total sugar contents. The $\mathrm{K}_{2} \mathrm{SO}_{4}$ promoted a best quality of green coffee.
\end{abstract}

Index terms: polyphenoloxidase, color index, total titrable acidity, sulfate, sugars.

\footnotetext{
${ }^{1}$ Aceito para publicação em 29 de junho de 1998.

${ }^{2}$ Eng. Agr., M.Sc., Doutorando do DCS/UFLA, EPAMIG, Caixa Postal 37, CEP 37200-000 Lavras, MG. E-mail: ebsilva@ufla.br

${ }^{3}$ Eng. Agr., D.Sc., EPAMIG, Caixa Postal 176, CEP 37200-000 Lavras, MG.

${ }^{4}$ Eng. Agr., M.Sc., EPAMIG.

${ }^{5}$ Farmacêutico-Bioquímico, M.Sc., EPAMIG.
}

\section{INTRODUÇÃO}

As exigências de K pelo cafeeiro são equivalentes às de $\mathrm{N}$, sendo este exigido em maior proporção durante o crescimento foliar. As quantidades de $\mathrm{K}$ nas partes vegetativas são suficientes para mostrar que este nutriente desempenha um papel importante na nutrição desta planta. 
Hiroce et al. (1975) não encontraram respostas ao K no Latossolo Roxo de São Simão e no Latossolo Vermelho orto de Campinas com aplicação de 0,83 e $166 \mathrm{~g} \mathrm{cova}^{-1}$ de K na cultivar Mundo Novo, apesar de observarem-se deficiências do K no final do ciclo, quando os teores nos solos estudados foram, respectivamente, de 15,6 e $156 \mathrm{mg} \mathrm{dm}^{-3}$.

Há uma correlação entre o teor de K no solo e a resposta do cafeeiro à aplicação de K. Malavolta (1986) afirma que a faixa adequada de K disponível no solo para cafeeiro é de 117 a $156 \mathrm{mg} \mathrm{dm}^{-3}$. Pavan et al. (1986) afirmam que teores de K no solo de $23,4 \mathrm{mg} \mathrm{dm}^{-3}$ limitam a produção, mas que, as produções máximas foram obtidas em parcelas com teores de $117 \mathrm{mg} \mathrm{dm}^{-3}$. Guimarães (1986) obteve respostas, em anos de alta produção, na faixa tida como adequada entre 112 e $150 \mathrm{mg} \mathrm{dm}^{-3}$, e em anos de baixa produção, entre 44 e $60 \mathrm{mg} \mathrm{dm}^{-3}$.

A cultura do cafeeiro é bastante exigente em $\mathrm{K}$, e o cloreto de potássio é o fertilizante mais utilizado. Esta fonte possui $47 \%$ de cloro, o que leva a planta a absorver e a acumular elevadas quantidades deste elemento. Admite-se que o cloreto $\left(\mathrm{Cl}^{-}\right)$tenha efeitos diretos e indiretos na qualidade da bebida. Amorim et al. (1973) relatam que em cafeeiros adubados com cloreto de potássio, o ânion $\mathrm{Cl}^{-}$pode exercer um efeito negativo na bebida. Como efeito indireto, Malavolta (1986) comenta que o excesso de K (ou do ânion acompanhante, $\mathrm{o} \mathrm{Cl}^{-}$) pode provocar uma queda maior de frutos que fermentam no solo, com conseqüente perda de qualidade do produto. Outra atuação do $\mathrm{Cl}^{-}$estaria em transferir à planta, uma umidade maior (Gouny, 1973); do que resultaria um ambiente de proliferação de microorganismos, o qual leva a fermentações indesejáveis, principalmente nos frutos de café, reduzindo assim a qualidade da bebida (Leite, 1991).

O potássio tem sido considerado, há muito tempo, como o "elemento da qualidade" em nutrição de plantas (Malavolta, 1980). A qualidade dos produtos agrícolas não é facilmente definida ou medida como se faz no tocante à produção. $\mathrm{O}$ padrão de qualidade depende dos propósitos pelos quais a planta ou parte dela é utilizada (Mengel \& Kirkby, 1987). No caso do café, o reflexo da adubação na produção é tão importante quanto os efeitos sobre os compostos orgânicos que identificam a qualidade da bebida desejada.
A qualidade do café se acha estreitamente relacionada com as diversas características físico-químicas e com os constituintes químicos responsáveis pelo sabor e aroma, que são característicos das bebidas. Entre os compostos, se sobressaem os açúcares, os ácidos, os compostos fenólicos, a cafeína, os compostos voláteis, os ácidos graxos, as proteínas e algumas enzimas, que, de acordo com seus teores e atividades, conferem ao café sabores e aromas peculiares (Amorim \& Silva, 1968; Feldman et al., 1969; Arcila-Pulgarin \& Valência-Aristizábal, 1975).

Os compostos químicos do grão de café cru dependem de fatores genéticos, influenciados pelo ambiente; das condições de manejo no campo; e do processamento do produto após a colheita. Dentro das condições de manejo, a adubação e a nutrição da planta podem influenciar na composição orgânica do grão verde, que após torrado produz compostos que conferem características de aroma e sabor do café.

As transformações bioquímicas que ocorrem no grão de café e que levam a uma depreciação da qualidade da bebida são, principalmente, de natureza enzimática. Estas transformações que envolvem glicosidases, polifenoloxidases, lipases e proteases, levam a uma degradação das paredes e membranas celulares, assim como as mudanças de coloração do grão, com conseqüente prejuízo na qualidade. A enzima polifenoloxidase é catalisada pelo micronutriente cobre (Malavolta, 1980; Robinson \& Eskin, 1991), a qual está correlacionada positivamente com a qualidade da bebida do café, como demonstraram Amorim \& Silva (1968), seguidos por Arcila-Pulgarin \& Valência-Aristizábal (1975), Leite (1991), Chagas (1994) e Carvalho et al. (1994).

Resultados recentes sobre a atividade da polifenoloxidase, índice de coloração, e a acidez titulável total, foram determinados por Carvalho et al. (1994), a partir de cafés de bebida previamente conhecida pela "prova da xícara", como: estritamente "mole", "apenas mole", "dura", "riada" e "rio", tendo estes autores concluído que a atividade da polifenoloxidase, e o índice de coloração aumentaram, enquanto a acidez decresceu com a melhoria da qualidade do café. Relataram ainda que estas análises possibilitaram classificar de forma objetiva os cafés quanto à qualidade, dando maior segurança às 
classificações feitas pelo teste subjetivo da "prova da xícara".

Em contribuição ao estudo dos efeitos de correlação entre carboidratos e a qualidade da bebida, Amorim et al. (1974) concluíram que a sua atuação não é específica, porque há grande variedade de compostos químicos que podem influenciar na qualidade da bebida. Em outro trabalho, Amorim et al. (1976) relataram que os teores de carboidratos decrescem com o armazenamento dos grãos e que os cafés de "bebida mole" possuem teores maiores de carboidratos do que cafés de pior qualidade. Entre os mono e oligossacarídeos, o carboidrato encontrado em maior quantidade no grão verde de café é a sacarose, e seu teor pode variar de 1,9 a $10 \%$ na matéria seca (Lockhart, 1957; Wolfrom et al., 1960; Feldman et al., 1969; Navellier, 1970), sendo considerado como açúcar não-redutor. Os monossacarídeos livres mais encontrados são a glicose e a frutose, sendo que na maioria dos trabalhos são calculados como açúcares redutores e variam de 0 a $5 \%$, segundo Lockhart (1957).

Segundo Amorim et al. (1965), há influência da adubação na qualidade do café, mas esses autores também afirmaram que os efeitos da adubação sobre a composição química do solo, do fruto e da bebida devem ser tratados com reserva, uma vez que os teores desses nutrientes (NPK), no grão e na polpa, não se correlacionam com os valores correspondentes à qualidade da bebida.

Em outro trabalho, Amorim et al. (1973) estudaram os efeitos da adubação NPK, sendo K na forma de cloreto, nos teores de macro e micronutrientes dos frutos e na qualidade da bebida, e obtiveram efeito negativo da adubação nitrogenada e potássica sobre a qualidade da bebida, o que confirma resultados de trabalho anterior (Amorim et al., 1967).

O presente trabalho foi conduzido com o objetivo de avaliar fontes e doses de $\mathrm{K}$ na produção e qualidade do grão de café beneficiado.

\section{MATERIAL E MÉTODOS}

O experimento de campo foi instalado na Fazenda Experimental da EPAMIG, em São Sebastião do Paraíso, MG, em fevereiro de 1993, em Latossolo Roxo distrófico, fase floresta tropical subperenifólia transicional para Cer- rado, textura argilosa, com as seguintes características na camada de 0 a $20 \mathrm{~cm}$ : argila, $440 \mathrm{~g} \mathrm{~kg}^{-1}$; silte, $220 \mathrm{~g} \mathrm{~kg}^{-1} \mathrm{e}$ areia, $340 \mathrm{~g} \mathrm{~kg}^{-1} ; \mathrm{pH}, 4,3 ; \mathrm{Ca}^{+2}, 13 ; \mathrm{Mg}^{+2}, 8 ; \mathrm{Al}^{+3}, 6 ;$ e CTC efetiva, 28 mmol $_{\mathrm{c}} \mathrm{dm}^{-3} ; \mathrm{K}^{+}, 55 \mathrm{e} \mathrm{P,} 2 \mathrm{mg} \mathrm{dm}^{-3}$; M.O., $31 \mathrm{~g} \mathrm{~kg}^{-1}$ segundo metodologia analítica de Raij et al. (1987).

O delineamento experimental foi em blocos casualizados no esquema de parcelas subdivididas, utilizando-se três fontes de $\mathrm{K}$ : cloreto de potássio $(\mathrm{KCl})$, sulfato de potássio $\left(\mathrm{K}_{2} \mathrm{SO}_{4}\right)$ e sulfato de potássio e magnésio $\left(\mathrm{K}_{2} \mathrm{SO}_{4} \cdot 2 \mathrm{MgSO}_{4}\right)$ nas parcelas e quatro doses de $\mathrm{K}(0$, 100,200 e $400 \mathrm{~g} \mathrm{cova}^{-1}$ de K) aplicadas nas subparcelas, com quatro repetições. A parcela experimental foi constituída de três linhas de oito covas, formando um total de 24 covas por parcela, sendo a parcela útil as seis covas centrais. Usou-se, neste experimento, a espécie Coffea arabica L., cultivar Catuaí Vermelho e linhagem LCH 2077-2-5-44 no espaçamento $3,5 \times 2,0 \mathrm{~m}$ plantado em dezembro de 1979, com duas plantas por cova.

$\mathrm{O}$ balanceamento do $\mathrm{Mg}$, $\mathrm{S}$ e Ca foi feito pelo uso de sulfato de magnésio, gesso agrícola e calcário calcítico. A adubação nitrogenada e fosfatada foi aplicada em doses recomendadas para lavoura do mesmo porte e idade, segundo a Comissão de Fertilidade do Solo do Estado de Minas Gerais (1989), com a utilização de fertilizantes não formulados, a uréia e o MAP. Antes da implantação, no ano de 1990, foi aplicado 4,5 tha ${ }^{-1}$ de calcário calcítico. Os tratamentos e a adubação básica foram parceladas em quatro vezes iguais a cada ano. Durante todo o período, o experimento recebeu aplicações de B e Zn via foliar para o controle preventivo de deficiências, além dos controles fitossanitários e dos tratos culturais.

A amostragem para as determinações dos teores de macro e micronutrientes nas folhas foi feita segundo recomendação de Malavolta (1993), ou seja, colhendo-se o terceiro e quarto pares de folhas a partir das pontas dos ramos laterais, inseridos na altura média da planta e ao redor da mesma, no verão. Os teores dos nutrientes nas folhas e grãos foram assim determinados: do extrato, obtido por digestão nitroperclórica (Malavolta et al., 1989), foram dosados os teores totais de $\mathrm{Mg}$ por espectrofotometria de absorção atômica; os de K, por fotometria de chama, e os de $\mathrm{S}$ total, por turbidimetria. $\mathrm{O} \mathrm{Cl}^{-}$foi determinado por titulação potenciométrica descrita por Lacroix et al. (1970).

Foram avaliadas as seguintes variáveis: a produção de grãos das seis covas úteis, colhida por derriça no pano, quando apresentavam aproximadamente $5 \%$ de frutos verdes. As quantidades de café limpo por parcela útil foram então convertidas em produção de sacas de $60 \mathrm{~kg}$ por hectare, sendo avaliadas duas colheitas, correspondentes aos anos de 1993 e 1994. As variáveis qualitativas foram de- 
terminadas em amostras de grãos beneficiados moídos em moinho tipo Croton Mod.TE-580, em peneira de 30 mesh, referente a cada tratamento aplicado, nos anos agrícolas de 1993 e 1994. Avaliou-se a atividade enzimática da polifenoloxidase determinada pelo método descrito por Ponting \& Joslyng (1948), utilizando-se o extrato da amostra sem DOPA (L-3,4 dihidroxifenil-alanina), como branco, expressa em $\mathrm{U} \mathrm{mim}^{-1} \mathrm{~g}^{-1}$ (Unidade de atividade enzimática por unidade de tempo em minutos por gramas de grãos beneficiados). A acidez titulável total foi determinada por titulação com $\mathrm{NaOH} 0,1 \mathrm{~mol} \mathrm{~L}^{-1}$, de acordo com técnica descrita pela Association of Official Analytical Chemists (1970), e expressa em mL de $\mathrm{NaOH} 100 \mathrm{~g}^{-1}$ de amostra. O índice de coloração foi determinado pelo método descrito por Singleton (1966) e adaptado para o café: pesaram-se $2 \mathrm{~g}$ da amostra de café moídos, que foram colocadas em erlenmeyer, adicionaram-se $50 \mathrm{~mL}$ de água destilada, agitando por uma hora, e fez-se a filtragem, tomandose $5 \mathrm{~mL}$ do filtrado e adicionando-se $10 \mathrm{~mL}$ de água destilada, ficando o extrato em repouso, por 20 minutos, para, em seguida, procederem-se as leituras em comprimento de ondas de $425 \mathrm{~nm}$, em espectrofotômetro. Os açúcares redutores, não-redutores e totais foram extraídos pelo método de Lane-Enyon, citado pela Association of Official Analytical Chemists (1970), e determinados pela técnica de Somogy, adaptada por Nelson (1944).

Os dados de produção e as variáveis qualitativas foram submetidos à análise de variância e regressão polinomial. Os teores de $\mathrm{K}, \mathrm{Mg}, \mathrm{S}$ e $\mathrm{Cl}$ nas folhas e nos grãos foram correlacionados (correlação linear simples) com os dados das variáveis qualitativas. Utilizaram-se os programas SANEST e SAEG para análise estatística, estabelecendose os níveis de significância de 5\% e 1\%.

\section{RESULTADOS E DISCUSSÃO}

Os efeitos de fontes e doses de K sobre a produção (sacas beneficiadas ha-1) nos dois anos estudados estão resumidos na Tabela 1.

Não houve diferenças entre as fontes e as doses de $\mathrm{K}$ aplicadas ao solo nem na interação entre estes fatores $(\mathrm{P}>0,05)$. Estes resultados concordam com os obtidos por Martins et al. (1981), que não encontraram diferenças na produção entre as fontes: nitrato de potássio $\left(\mathrm{KNO}_{3}\right)$, sulfato de potássio $\left(\mathrm{K}_{2} \mathrm{SO}_{4}\right)$, sulfato de potássio e magnésio $\left(\mathrm{K}_{2} \mathrm{SO}_{4} \cdot 2 \mathrm{MgSO}_{4}\right)$ e cloreto de potássio $(\mathrm{KCl})$. Segundo esses autores, o teor de K no solo, por ocasião da instalação do experimento era de $25 \mathrm{mg} \mathrm{dm}^{-3}$, e no presente experimento era de $55 \mathrm{mg} \mathrm{dm}^{-3}$, teor este mais elevado, mas que não eqüivale à necessidade da cultura, uma vez que o teor crítico de K no solo, segundo Guimarães (1986), é de $112 \mathrm{mg} \mathrm{dm}^{-3}$ para ano de alta produção, e de $44 \mathrm{mg} \mathrm{dm}^{-3}$, para ano de baixa produção.

A resposta do cafeeiro à aplicação de $\mathrm{K}$, depende do teor de $\mathrm{K}$ disponível e de sua reposição no solo. $\mathrm{O}$ teor de $\mathrm{K}$ na área experimental estava acima do limite encontrado por Pavan et al. (1986) de $23 \mathrm{mg} \mathrm{dm}^{-3}$. Hiroce et al. (1975) não obtiveram resposta à adubação potássica em dois solos, quando os teores foram de 15,6 e $156 \mathrm{mg} \mathrm{dm}^{-3}$, teores estes abaixo e acima daquele encontrado na área experimental.

Malavolta (1986) propôs uma faixa ideal de K, no solo, em torno de 117 a $156 \mathrm{mg} \mathrm{dm}^{-3}$, para obter produção compensadora, teores estes acima do contido na análise inicial do presente trabalho mas, mesmo assim, não se observou resposta à adubação potássica nas condições experimentais.

Não ocorreram respostas às fontes e doses de $\mathrm{K}$ nos dois anos avaliados. A análise textural do solo da área experimental revelou um teor de silte de $220 \mathrm{~g} \mathrm{~kg}^{-1}$; embora não se tenha feito análise

TABELA 1. Produção (sacas beneficiadas de $60 \mathrm{~kg} \mathrm{ha}^{-1}$ ) de dois anos agrícolas.

\begin{tabular}{lccc}
\hline Fonte & $\begin{array}{c}\text { Doses de } \mathrm{K} \\
\left(\mathrm{g} \mathrm{cova}^{-1}\right)\end{array}$ & \multicolumn{2}{c}{ Produção } \\
\cline { 3 - 4 } & 0 & 32,3 & 38,4 \\
$\mathrm{KCl}$ & 100 & 38,1 & 39,6 \\
& 200 & 31,4 & 33,3 \\
& 400 & 32,4 & 32,4 \\
\hline Média & & 33,6 & 35,9 \\
\hline $\mathrm{K}_{2} \mathrm{SO}_{4}$ & 0 & 29,4 & 50,8 \\
& 100 & 29,0 & 45,0 \\
& 200 & 38,2 & 56,0 \\
& 400 & 31,2 & 38,8 \\
\hline Média & & 32,0 & 47,6 \\
\hline $\mathrm{K}_{2} \mathrm{SO}_{4} \cdot 2 \mathrm{MgSO}_{4}$ & 0 & 31,0 & 37,4 \\
& 100 & 41,0 & 28,4 \\
& 200 & 35,8 & 41,1 \\
& 400 & 30,8 & 44,3 \\
\hline Média & & 34,7 & 37,8 \\
\hline Média geral & & 33,4 & 40,4 \\
\hline
\end{tabular}


mineralógica desta fração, especula-se que a mesma tenha reserva de K e esteja contribuindo para a reposição do K disponível. Observa-se, pela Tabela 1, que não existe diferença de produção entre as médias das fontes de $\mathrm{K}$ que apresentaram, respectivamente, 33,6, 32,0 e 34,7 sacas ha ${ }^{-1}$ nas fontes $\mathrm{KCl}$, $\mathrm{K}_{2} \mathrm{SO}_{4}$ e K $\mathrm{SO}_{4} .2 \mathrm{MgSO}_{4}$, no ano de 1993. No ano de 1994 , a fonte $\mathrm{K}_{2} \mathrm{SO}_{4}$ apresentou a maior produção (47,6 sacas ha-1), seguida pelo $\mathrm{K}_{2} \mathrm{SO}_{4} \cdot 2 \mathrm{MgSO}_{4}$ $(40,4$ sacas ha-1) e menor produção no $\mathrm{KCl}$ $\left(35,9\right.$ sacas ha $\left.^{-1}\right)$.

Houve diferenças significativas $(\mathrm{P}<0,01)$ entre os valores de atividade da polifenoloxidase nas fontes estudadas nos anos de 1993 e 1994 (Tabela 2). A maior atividade da enzima polifenoloxidase foi observada nas amostras que receberam a aplicação de $\mathrm{K}_{2} \mathrm{SO}_{4}$, na qual se obtiveram, no ano de 1993 , valores de 63,12 e $63,18 \mathrm{U} \mathrm{min}^{-1} \mathrm{~g}^{-1}$ de amostra; no $\mathrm{K}_{2} \mathrm{SO}_{4} \cdot 2 \mathrm{MgSO}_{4}$, obtiveram-se valores de atividade de 57,81 e 59,10 $\mathrm{U} \mathrm{min}^{-1} \mathrm{~g}^{-1}$ de amostra, e, no KCl, 56,90 e $59,36 \mathrm{U} \mathrm{min}^{-1} \mathrm{~g}^{-1}$ de amostra, respectivamente, nos anos de 1993 e 1994.

$\mathrm{O}$ sulfato de potássio $\left(\mathrm{K}_{2} \mathrm{SO}_{4}\right)$ proporcionou maior atividade da polifenoloxidase, variável esta que expressa uma melhor qualidade do café, conforme Amorim \& Silva (1968), Arcila-Pulgarin \& ValênciaAristizábal (1975), Leite (1991), Carvalho et al. (1994) e Chagas (1994). Na literatura disponível, pertinente a esta linha de pesquisa, são escassos os trabalhos, não havendo, portanto, resultados que permitam estabelecer comparações concludentes entre fontes de nutrientes e a atividade da polifenoloxidase.

Apesar das diferenças estatísticas quanto à atividade da polifenoloxidase de grãos de café de plantas adubadas com diferentes fontes de $\mathrm{K}$, nos dois anos estudados, os valores desta atividade enzimática foram próximos do obtido por Leite (1991), no mesmo local de cultivo (São Sebastião do Paraíso), de $57,46 \mathrm{U} \mathrm{min}^{-1} \mathrm{~g}^{-1}$ de amostra de cafés derriçados no pano, idêntico ao modo de colheita deste experimento. $\mathrm{Na}$ fonte $\mathrm{K}_{2} \mathrm{SO}_{4}$, a atividade da polifenoloxidase, neste trabalho, foi superior ao encontrado pelo referido autor, mostrando, assim, um efeito favorável desta fonte.

Segundo Carvalho et al. (1994), a determinação da atividade da polifenoloxidase permite avaliar, de modo objetivo, a qualidade do café, estabelecendo a seguinte classificação, complementar à estabelecida pela "prova da xícara": Café extra fino ("bebida estritamente mole") - atividade da polifenoloxidase superior a $67,66 \mathrm{U} \mathrm{min}^{-1} \mathrm{~g}^{-1}$ de amostra; fino ("bebida mole e apenas mole") - atividade da polifenoloxidase de 62,99 a 67,66 U min ${ }^{-1} \mathrm{~g}^{-1}$ de amostra; aceitável ("bebida dura") - atividade da polifenoloxidase de 55,99 a 62,99 U min-1 $\mathrm{g}^{-1}$ de amostra; não-aceitável ("bebida riada e rio") - atividade de polifenoloxidase inferior a 55,99 $\mathrm{U} \mathrm{min}^{-1} \mathrm{~g}^{-1}$ de amostra.

Comparando os resultados obtidos no presente trabalho com os de Carvalho et al. (1994), observa-se que os valores da atividade da polifenoloxidase,

TABELA 2. Atividade da polifenoloxidase, acidez titulável total, índice de coloração, açúcares redutores em função de fontes de $\mathrm{K}\left(\mathrm{KCl}, \mathrm{K}_{2} \mathrm{SO}_{4}\right.$ e $\left.\mathrm{K}_{2} \mathrm{SO}_{4} .2 \mathrm{MgSO}_{4}\right)$ nos anos agrícolas 1992/93 e 1993/941.

\begin{tabular}{|c|c|c|c|c|c|c|c|c|}
\hline \multirow[t]{2}{*}{ Fonte } & \multicolumn{2}{|c|}{$\begin{array}{c}\text { Atividade da } \\
\text { polifenoloxidase } \\
\left(\mathrm{U} \min ^{-1} \mathrm{~g}^{-1}\right) \\
\end{array}$} & \multicolumn{2}{|c|}{$\begin{array}{c}\text { Acidez } \\
\text { titulável total } \\
\left(\mathrm{mL} \mathrm{NaOH} 100 \mathrm{~g}^{-1}\right)\end{array}$} & \multicolumn{2}{|c|}{$\begin{array}{c}\text { Índice } \\
\text { de coloração } \\
\text { (D.O. } 425 \mathrm{~nm} \text { ) }\end{array}$} & \multicolumn{2}{|c|}{$\begin{array}{c}\text { Açúcares } \\
\text { redutores } \\
(\%) \\
\end{array}$} \\
\hline & $1992 / 93$ & $1993 / 94$ & $1992 / 93$ & $1993 / 94$ & $1992 / 93$ & $1993 / 94$ & $1992 / 93$ & 1993/94 \\
\hline $\mathrm{KCl}$ & $56,90 \mathrm{~b}$ & $59,36 \mathrm{~b}$ & $333 b$ & $329 a$ & $0,803 a$ & $1,025 b$ & $0,44 \mathrm{a}$ & $0,32 \mathrm{a}$ \\
\hline $\mathrm{K}_{2} \mathrm{SO}_{4}$ & $63,12 \mathrm{a}$ & $63,18 \mathrm{a}$ & $325 b$ & $305 b$ & $0,848 \mathrm{a}$ & $1,358 \mathrm{a}$ & $0,42 \mathrm{a}$ & $0,26 b$ \\
\hline$\underline{\mathrm{K}_{2} \mathrm{SO}_{4} \cdot 2 \mathrm{MgSO}_{4}}$ & $57,81 \mathrm{~b}$ & $59,10 \mathrm{~b}$ & $359 \mathrm{a}$ & $295 \mathrm{~b}$ & $0,798 \mathrm{a}$ & $1,241 \mathrm{a}$ & $0,40 \mathrm{a}$ & $0,25 b$ \\
\hline DMS (5\%) & 3,49 & 3,11 & 25,90 & 23,49 & 0,160 & 0,130 & 0,11 & 0,03 \\
\hline C.V. (\%) & 2,72 & 2,36 & 3,52 & 3,55 & 9,06 & 5,15 & 11,99 & 5,82 \\
\hline
\end{tabular}

${ }^{1}$ Médias seguidas da mesma letra, na coluna, não diferem entre si pelo teste de Tukey a $5 \%$ de probabilidade. 
quando se usou o $\mathrm{K}_{2} \mathrm{SO}_{4}$ foram de 63,12 , e 63,18 $\mathrm{U} \mathrm{min}^{-1} \mathrm{~g}^{-1}$ de amostra, nos anos de $1993 \mathrm{e}$ 1994, respectivamente classificados como finos ("bebida mole" e "apenas mole"), de 56,90 e $59,36 \mathrm{U} \mathrm{min}^{-1} \mathrm{~g}^{-1}$ de amostra, quando se usou o $\mathrm{KCl}$ e de 57,81 e 59,10 $\mathrm{U} \mathrm{min}^{-1} \mathrm{~g}^{-1}$ de amostra, quando se usou o $\mathrm{K}_{2} \mathrm{SO}_{4} .2 \mathrm{MgSO}_{4}$, nos anos de 1993 e 1994, respectivamente, classificados como aceitáveis ("bebida dura").

Pela análise de variância houve diferenças significativas entre fontes de $\mathrm{K}(\mathrm{P}<0,05)$ na avaliação dos valores de acidez titulável total em ambos os anos. Pela Tabela 2, observa-se que no ano de 1993, os mais baixos valores de acidez foram encontrados nas amostras de $\mathrm{K}_{2} \mathrm{SO}_{4}$ e $\mathrm{KCl}$, ou seja, de 325 e $333 \mathrm{~mL}$ de $\mathrm{NaOH} 100 \mathrm{~g}^{-1}$ de amostra, respectivamente. O maior índice foi obtido na amostra de $\mathrm{K}_{2} \mathrm{SO}_{4} \cdot 2 \mathrm{MgSO}_{4}$, com um valor de $359 \mathrm{~mL}$ de $\mathrm{NaOH} 100 \mathrm{~g}^{-1}$ de amostra. No ano de 1994, a maior acidez foi obtida quando se usou o $\mathrm{KCl}$, ou seja, $329 \mathrm{~mL}$ de $\mathrm{NaOH} 100 \mathrm{~g}^{-1}$ de amostra, e os mais baixos índices de acidez foram nas amostras $\mathrm{K}_{2} \mathrm{SO}_{4} \cdot 2 \mathrm{MgSO}_{4}$ e $\mathrm{K}_{2} \mathrm{SO}_{4}$, valores de 305 e $295 \mathrm{~mL}$ de $\mathrm{NaOH} 100 \mathrm{~g}^{-1}$ de amostra, respectivamente.

Leite (1991), Carvalho et al. (1994) e Chagas (1994) observaram que se a atividade de polifenoloxidase aumenta, a acidez diminui, em amostras de café, havendo, portanto, uma relação inversa. No presente experimento, em ambos os anos, a mesma ocorrência foi observada no tratamento com $\mathrm{K}_{2} \mathrm{SO}_{4}$.

Os resultados dos tratamentos com $\mathrm{K}_{2} \mathrm{SO}_{4} \cdot 2 \mathrm{MgSO}_{4}$, em 1993, não foram concordantes com a relação inversa existente entre a atividade da polifenoloxidase e acidez titulável total. Esta discrepância pode ser atribuída à infecção por microrganismos na fase pós-colheita, observadas nas amostras deste tratamento. A ação dos microrganismos, produzindo acidez pela fermentação, desdobrando os açúcares presentes na mucilagem, completa-se também com a produção de álcool e dos ácidos acético, propiônico e butírico. A partir deste último, já se observam prejuízos acentuados na qualidade.

Os resultados referentes ao índice de coloração encontram-se na Tabela 2. Observa-se que não houve diferença no índice de coloração no ano de 1993 $(\mathrm{P}>0,05)$, mas houve diferença significativa entre as fontes de $\mathrm{K}(\mathrm{P}<0,01)$, em 1994. Os maiores índices de coloração foram observados em amostras de grãos de café quando se usou o $\mathrm{K}_{2} \mathrm{SO}_{4}(1,358)$ e o $\mathrm{K}_{2} \mathrm{SO}_{4} \cdot 2 \mathrm{MgSO}_{4}(1,241)$, que não se diferenciaram entre si, porém ambos foram estatisticamente diferentes do obtido na fonte $\mathrm{KCl}(1,025)$.

Segundo Carvalho et al. (1994), o índice de coloração permite separar cafés de bebidas "riada" e "rio", ou seja, bebida não aceitável (valores deste índice inferiores a 0,650 ), dos cafés de bebidas "dura" (aceitável), "mole", "apenas mole" (finos) e "estritamente mole" (extras finos), com índice de coloração iguais ou superiores a 0,650 . Portanto, pode-se verificar, pelos valores do índice de coloração entre as fontes de $\mathrm{K}$, que os cafés poderiam ter uma bebida, no mínimo, aceitável ("dura"), quando comparados com os daqueles autores.

As amostras de grãos de café da fonte $\mathrm{K}_{2} \mathrm{SO}_{4}$, em 1994, proporcionaram maior índice de coloração, apesar de não serem diferentes das amostras obtidas com o $\mathrm{K}_{2} \mathrm{SO}_{4} .2 \mathrm{MgSO}_{4}$, e foram também as que apresentaram maior atividade da polifenoloxidase. Estes parâmetros são indicadores de cafés de melhor qualidade, segundo Leite (1991), Carvalho et al. (1994) e Chagas (1994).

Leite (1991) e Carvalho et al. (1994) verificaram que cafés de melhor qualidade possuem maior atividade da enzima polifenoloxidase, menor acidez titulável total e maior índice de coloração. Portanto, verificou-se a existência de uma identidade destas variáveis com a qualidade, e de uma relação entre os cafés, no ano de 1994, o que confirma que a fonte $\mathrm{K}_{2} \mathrm{SO}_{4}$ proporcionou um café de melhores atributos ou características de maior valor.

Na avaliação dos açúcares, no ano de 1993, não houve diferenças significativas $(\mathrm{P}>0,05)$. No ano de 1994, houve efeito significativo entre fontes de K $(\mathrm{P}<0,05)$ com relação a açúcares redutores. Quanto a açúcares não-redutores, houve interação mais relevante entre as fontes e doses de $\mathrm{K}(\mathrm{P}<0,01)$ e também em relação aos açúcares totais $(\mathrm{P}<0,01)$.

Pela Tabela 2, observa-se um maior teor de açúcares redutores de $0,32 \%$ na fonte $\mathrm{KCl}$, que foi estatisticamente superior aos teores de $0,26 \%$, e $0,25 \%$ quando se usaram o $\mathrm{K}_{2} \mathrm{SO}_{4}$ e o $\mathrm{K}_{2} \mathrm{SO}_{4} \cdot 2 \mathrm{MgSO}_{4}$, respectivamente. Os resultados obtidos entre as fontes estão dentro da faixa citada por Lockhart (1957), que variam de 0 a $5 \%$ de açúcares redutores. Leite (1991) 
encontrou, em amostras colhidas em São Sebastião do Paraíso, um teor de $0,06 \%$ de açúcares redutores. Este teor é baixo em relação ao encontrado no presente experimento. Nota-se que houve um efeito da adubação potássica nos teores de açúcares redutores.

Pela Fig. 1A, observa-se um efeito quadrático, com o aumento das doses de $\mathrm{K}_{2} \mathrm{SO}_{4}$, sobre os teores de açúcares não-redutores nos grãos beneficiados. $\mathrm{O}$ teor máximo foi obtido na dose de $214 \mathrm{~g} \mathrm{cova}^{-1} \mathrm{de} \mathrm{K}$, atingindo um teor de 5,14\%. Com aumento das doses de $\mathrm{KCl}$ houve uma redução linear dos teores de açúcares não-redutores, sendo o teor máximo na ausência da aplicação de K, com teor de 5,81\%. Para $\mathrm{K}_{2} \mathrm{SO}_{4} \cdot 2 \mathrm{MgSO}_{4}$, não houve diferença significativa nos teores de açúcares não-redutores, tendo um teor médio de $4,48 \%$. Os teores encontrados estão próximos, acima e abaixo do teor obtido por Wolfrom et al. (1960), que encontraram um teor de 5,30\%, para $\mathrm{K}_{2} \mathrm{SO}_{4}, \mathrm{KCl} \mathrm{e} \mathrm{S}_{2} \mathrm{SO}_{4} \cdot 2 \mathrm{MgSO}_{4}$, respectivamente.

Observa-se, ainda, na Fig. 1B, um efeito quadrático entre os teores de açúcares totais com o aumento das doses de $\mathrm{K}_{2} \mathrm{SO}_{4}$. O teor máximo foi obtido com a dose de $209 \mathrm{~g} \mathrm{cova}^{-1}$ de $\mathrm{K}$, atingindo um teor de 5,63\%. Para o $\mathrm{KCl}$ houve redução linear, semelhante aos açúcares não-redutores, com teor máximo obtido na ausência de $\mathrm{K}$, atingindo um teor de $6,37 \%$. No $\mathrm{K}_{2} \mathrm{SO}_{4} .2 \mathrm{MgSO}_{4}$, não ocorreu diferença significati- va, com teor médio de 4,94\%. Os teores encontrados mostram-se inferiores ao valor médio observado por Navellier (1970), quando encontrou um teor de 8\% de açúcares totais.

Os carboidratos podem contribuir para o sabor e aroma do café (Amorim et al., 1974), mas estes componentes não participam das classificações oficiais de qualidade da bebida, embora Amorim et al. (1976) e Chagas (1994) afirmem que os melhores cafés possuem maiores teores de açúcares totais.

De modo geral, para o $\mathrm{K}_{2} \mathrm{SO}_{4}$ apresentou-se uma resposta superior, na avaliação dos teores açúcares totais e da atividade polifenoloxidase, diferenciada das outras fontes. No $\mathrm{K}_{2} \mathrm{SO}_{4}$ também ocorreu maior índice de coloração e menor acidez titulável total, mostrando, assim, que o $\mathrm{K}_{2} \mathrm{SO}_{4}$ propiciou, no ano de 1994, cafés de melhor qualidade.

Na composição físico-química e química dos grãos beneficiados de café, ocorreram mais variáveis qualitativas significativas no ano de 1994, do que em 1993, provavelmente pelo fato de a aplicação dos tratamentos terem sido feitos em março de 1993, com tempo insuficiente para influenciar estas variáveis no próprio ano.

Foram realizadas correlações lineares simples entre os teores de $\mathrm{K}, \mathrm{Mg}, \mathrm{S}$ e Cl nas folhas e nos grãos com as variáveis qualitativas dos grãos beneficiados no ano de 1994, cujos coeficientes e significâncias
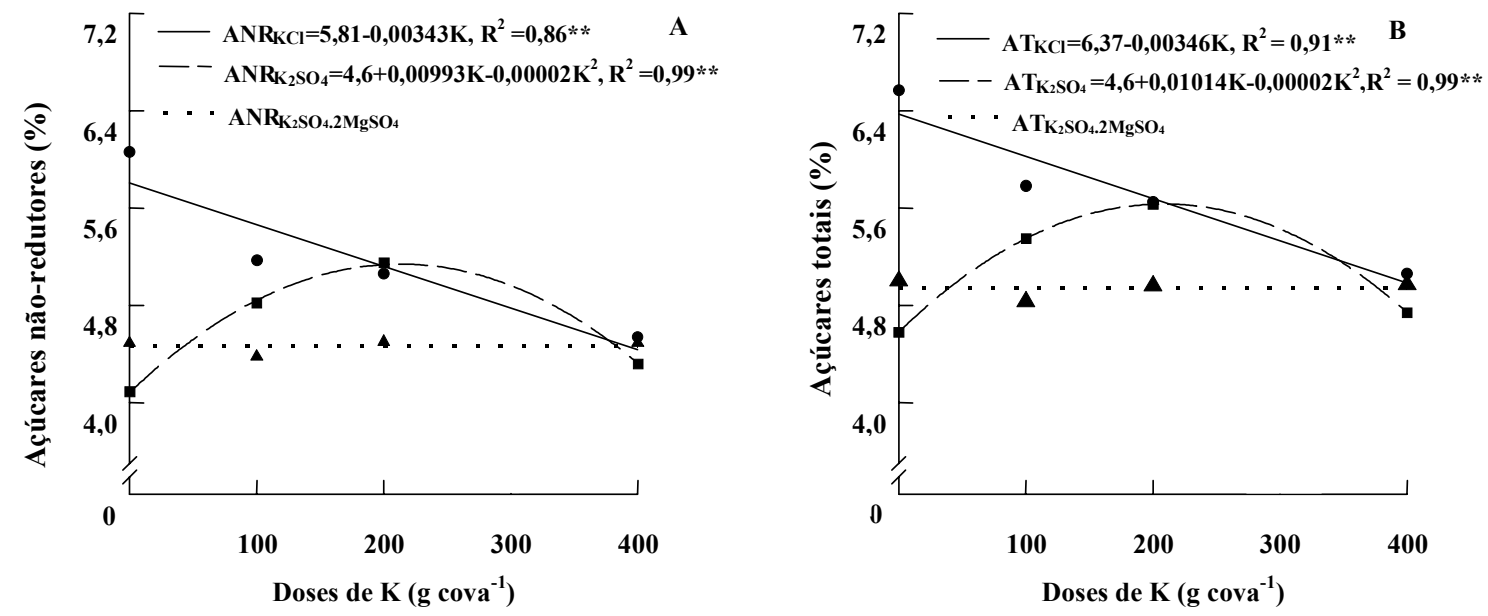

FIG. 1. Teores de açúcares não-redutores (A) e totais (B) em função de doses de $\mathrm{K}$ nas fontes $\mathrm{KCl}, \mathrm{K}_{2} \mathrm{SO}_{4}$ e $\mathrm{K}_{2} \mathrm{SO}_{4} .2 \mathrm{MgSO}_{4}, 1994$. 
são mostrados na Tabela 3, e os teores dos nutrientes em função das fontes e doses de $\mathrm{K}$ na Tabela 4.

Observou-se que, de maneira geral, são poucas as correlações significativas entre os teores dos nutrientes nas folhas e nos grãos com as variáveis qualitativas dos grãos, apresentando, também, valores dos coeficientes bastante baixos, mas algumas são dignas de destaque e serão discutidas a seguir.

A Tabela 2 mostra que a atividade da polifenoloxidase no ano de 1994 foi estatisticamente superior, quando se aplicou o $\mathrm{K}_{2} \mathrm{SO}_{4}$, mas sem haver diferença entre o $\mathrm{K}_{2} \mathrm{SO}_{4} \cdot 2 \mathrm{MgSO}_{4}$ e $\mathrm{KCl}$. Uma possível explicação de uma menor atividade enzimática no
$\mathrm{KCl}$ talvez seja a correlação negativa entre a enzima e o teor de $\mathrm{Cl}$ nas folhas, o que não foi observado no tocante aos grãos (Tabela 3), mas em ambas as partes ocorre um aumento do teor de $\mathrm{Cl}$ com aumento das doses de $\mathrm{KCl}$ (Tabela 4). A enzima polifenoloxidase é uma enzima cúprica (Malavolta, 1980), da qual o Cu é componente e ativador. Segundo Robinson \& Eskin (1991), o Cu é um livre catalisador da enzima, mas o $\mathrm{Cl}$ inibe sua atividade devido à interação ou reação com aquele metal, induzindo uma redução na atividade enzimática na fonte $\mathrm{KCl}$.

Por outro lado, em plantas que recebem $\mathrm{Cl}$ aumenta-se o conteúdo de água (Gouny, 1973). É pos-

TABELA 3. Coeficientes de correlação linear simples entre os teores de nutrientes $\mathrm{K}$, $\mathrm{Mg}$, $\mathrm{S}$ e $\mathrm{Cl}$ das folhas e dos grãos ( $\mathrm{g} \mathrm{kg}^{-1}$ de MS) com as variáveis qualitativas dos grãos de café beneficiados no ano agrícola 1993/94, para cada fonte utilizada ${ }^{1}$.

\begin{tabular}{|c|c|c|c|c|c|c|c|c|}
\hline \multirow[t]{3}{*}{ Variáveis ${ }^{2}$} & \multicolumn{8}{|c|}{ Nutrientes } \\
\hline & \multicolumn{2}{|c|}{ K } & \multicolumn{2}{|c|}{$\mathrm{Mg}$} & \multicolumn{2}{|c|}{$\mathrm{S}$} & \multicolumn{2}{|c|}{$\mathrm{Cl}$} \\
\hline & Folha & Grão & Folha & Grão & Folha & Grão & Folha & Grão \\
\hline & & & & 25NG & & & & \\
\hline PFO & $-0,61 * *$ & $-0,12 \mathrm{NS}$ & $0,08 \mathrm{NS}$ & $0,25 \mathrm{NS}$ & $-0,13 \mathrm{NS}$ & $0,18 \mathrm{NS}$ & $-0,77 * *$ & $-0,30 \mathrm{NS}$ \\
\hline ATT & $-0,12 \mathrm{NS}$ & $0,39 \mathrm{NS}$ & $0,22 \mathrm{NS}$ & $0,04 \mathrm{NS}$ & $-0,12 \mathrm{NS}$ & $-0,03 \mathrm{NS}$ & $-0,33 \mathrm{NS}$ & $0,16 \mathrm{NS}$ \\
\hline IC & $0,29 \mathrm{NS}$ & $0,26 \mathrm{NS}$ & $-0,45^{*}$ & $-0,50^{*}$ & $0,36 \mathrm{NS}$ & $0,46^{*}$ & $0,04 \mathrm{NS}$ & $-0,02 \mathrm{NS}$ \\
\hline $\mathrm{AR}$ & $-0,08 \mathrm{NS}$ & $0,19 \mathrm{NS}$ & $0,18 \mathrm{NS}$ & $-0,08 \mathrm{NS}$ & $-0,04 \mathrm{NS}$ & $-0,41 *$ & $0,22 \mathrm{NS}$ & $0,06 \mathrm{NS}$ \\
\hline ANR & $-0,28 \mathrm{NS}$ & $-0,08 \mathrm{NS}$ & $-0,02 \mathrm{NS}$ & $0,47^{*}$ & $-0,03 \mathrm{NS}$ & $-0,18 \mathrm{NS}$ & $-0,53^{*}$ & $-0,13 \mathrm{NS}$ \\
\hline AT & $-0,24 \mathrm{NS}$ & $-0,01 \mathrm{NS}$ & $-0,01 \mathrm{NS}$ & $0,41 *$ & $-0,01 \mathrm{NS}$ & $-0,24 \mathrm{NS}$ & $-0,46^{*}$ & $-0,07 \mathrm{NS}$ \\
\hline & & & & & & & & \\
\hline PFO & $-0,02 \mathrm{NS}$ & $0,12 \mathrm{NS}$ & $-0,07 \mathrm{NS}$ & $0,30 \mathrm{NS}$ & $-0,32 \mathrm{NS}$ & $0,05 \mathrm{NS}$ & $0,06 \mathrm{NS}$ & $0,09 \mathrm{NS}$ \\
\hline ATT & $-0,08 \mathrm{NS}$ & $0,04 \mathrm{NS}$ & $-0,06 \mathrm{NS}$ & $0,15 \mathrm{NS}$ & $0,17 \mathrm{NS}$ & $-0,24 \mathrm{NS}$ & $0,16 \mathrm{NS}$ & $0,09 \mathrm{NS}$ \\
\hline IC & $0,29 \mathrm{NS}$ & $0,50^{*}$ & $0,26 \mathrm{NS}$ & $0,24 \mathrm{NS}$ & $0,04 \mathrm{NS}$ & $0,06 \mathrm{NS}$ & $0,06 \mathrm{NS}$ & $-0,25 \mathrm{NS}$ \\
\hline $\mathrm{AR}$ & $-0,04 \mathrm{NS}$ & $-0,26 \mathrm{NS}$ & $-0,54^{*}$ & $-0,29 \mathrm{NS}$ & $0,05 \mathrm{NS}$ & $0,04 \mathrm{NS}$ & $-0,07 \mathrm{NS}$ & $0,26 \mathrm{NS}$ \\
\hline ANR & $0,47 *$ & $0,47^{*}$ & $-0,01 \mathrm{NS}$ & $0,49^{*}$ & $0,60^{* *}$ & $0,63^{* *}$ & $-0,15 \mathrm{NS}$ & $0,09 \mathrm{NS}$ \\
\hline AT & $0,43^{*}$ & $0,42 *$ & $-0,06 \mathrm{NS}$ & $0,48^{* *}$ & $0,60 * *$ & $0,62 * *$ & $-0,15 \mathrm{NS}$ & $0,04 \mathrm{NS}$ \\
\hline & 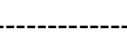 & - & - & $-\mathrm{K}_{2} \mathrm{SO}_{4}$ & $\mathrm{SO}_{4}$ & - & & - \\
\hline PFO & $-0,04 \mathrm{NS}$ & $-0,05 \mathrm{NS}$ & $-0,03 \mathrm{NS}$ & $-0,29 \mathrm{NS}$ & $0,09 \mathrm{NS}$ & $-0,28 \mathrm{NS}$ & $-0,01 \mathrm{NS}$ & $0,02 \mathrm{NS}$ \\
\hline ATT & $-0,14 \mathrm{NS}$ & $-0,10 \mathrm{NS}$ & $-0,01 \mathrm{NS}$ & $-0,11 \mathrm{NS}$ & $-0,48^{*}$ & $-0,12 \mathrm{NS}$ & $-0,31 \mathrm{NS}$ & $-0,08 \mathrm{NS}$ \\
\hline IC & $-0,31 \mathrm{NS}$ & $-0,08 \mathrm{NS}$ & $0,24 \mathrm{NS}$ & $-0,16 \mathrm{NS}$ & $-0,32 \mathrm{NS}$ & $0,32 \mathrm{NS}$ & $-0,03 \mathrm{NS}$ & $0,03 \mathrm{NS}$ \\
\hline AR & $0,01 \mathrm{NS}$ & $-0,02 \mathrm{NS}$ & $0,30 \mathrm{NS}$ & $-0,04 \mathrm{NS}$ & $-0,30 \mathrm{NS}$ & $0,23 \mathrm{NS}$ & $0,07 \mathrm{NS}$ & $0,20 \mathrm{NS}$ \\
\hline ANR & $0,06 \mathrm{NS}$ & $-0,02 \mathrm{NS}$ & $-0,19 \mathrm{NS}$ & $-0,29 \mathrm{NS}$ & $-0,08 \mathrm{NS}$ & $-0,05 \mathrm{NS}$ & $-0,45^{*}$ & $0,24 \mathrm{NS}$ \\
\hline AT & $0,06 \mathrm{NS}$ & $-0,02 \mathrm{NS}$ & $-0,16 \mathrm{NS}$ & $-0,30 \mathrm{NS}$ & $-0,11 \mathrm{NS}$ & $-0,02 \mathrm{NS}$ & $-0,44 *$ & $0,26 \mathrm{NS}$ \\
\hline
\end{tabular}

$1 \mathrm{NS}, *$ e $* *$ Não significativo e significativo a 5 e $1 \%$ de probabilidade, respectivamente.

2 PFO: atividade de polifenoloxidase; ATT: acidez titulável total; IC: índice de coloração; AR: açúcares redutores; ANR: açúcares não-redutores; AT: açúcares totais. 
TABELA 4. Teores de $\mathrm{K}, \mathrm{Mg}$, $\mathrm{S}$ e Cl das folhas e dos grãos de café ( $\mathrm{g} \mathrm{kg}^{-1}$ de MS) em função das doses de K no ano agrícola 1993/94, para cada fonte utilizada.

\begin{tabular}{|c|c|c|c|c|c|c|c|c|}
\hline \multirow{3}{*}{$\begin{array}{r}\text { Doses de } \mathrm{K} \\
\left(\mathrm{g} \mathrm{cova}^{-1}\right)\end{array}$} & \multicolumn{8}{|c|}{ Nutrientes } \\
\hline & \multicolumn{2}{|c|}{$\mathrm{K}$} & \multicolumn{2}{|c|}{$\mathrm{Mg}$} & \multicolumn{2}{|c|}{$\mathrm{S}$} & \multicolumn{2}{|c|}{$\mathrm{Cl}$} \\
\hline & Folha & Grão & Folha & Grão & Folha & Grão & Folha & Grão \\
\hline & \multicolumn{8}{|c|}{ 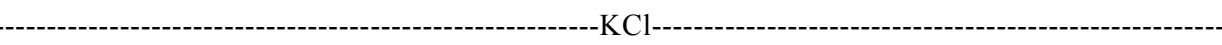 } \\
\hline 0 & 20,13 & 17,10 & 4,80 & 2,17 & 2,00 & 1,29 & 0,99 & 0,32 \\
\hline 100 & 22,67 & 17,62 & 4,60 & 1,97 & 2,12 & 1,57 & 2,02 & 0,33 \\
\hline 200 & 23,45 & 17,52 & 4,92 & 2,15 & 2,10 & 1,50 & 2,91 & 0,35 \\
\hline 400 & 24,52 & 17,07 & 4,65 & 2,07 & 1,95 & 1,17 & 3,27 & 0,37 \\
\hline \multirow[t]{2}{*}{ Média } & 22,69 & 17,33 & 4,74 & 2,09 & 2,04 & 1,38 & 2,29 & 0,34 \\
\hline & \multicolumn{8}{|c|}{ 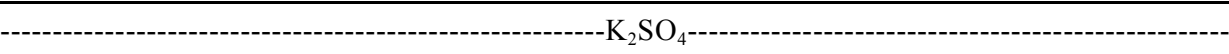 } \\
\hline 0 & 20,57 & 13,67 & 4,67 & 1,97 & 2,00 & 0,97 & 1,13 & 0,28 \\
\hline 100 & 25,10 & 14,20 & 4,60 & 2,00 & 2,10 & 1,30 & 0,98 & 0,28 \\
\hline 200 & 24,95 & 15,05 & 5,15 & 2,12 & 2,13 & 1,32 & 1,12 & 0,27 \\
\hline 400 & 25,95 & 14,85 & 5,30 & 1,92 & 2,15 & 1,10 & 1,14 & 0,24 \\
\hline \multirow[t]{2}{*}{ Média } & 24,14 & 14,44 & 4,93 & 2,00 & 2,09 & 1,17 & 1,09 & 0,26 \\
\hline & \multicolumn{8}{|c|}{ 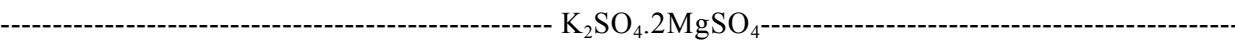 } \\
\hline 0 & 23,42 & 15,12 & 4,72 & 1,93 & 1,75 & 1,33 & 0,96 & 0,28 \\
\hline 100 & 26,60 & 15,17 & 4,52 & 2,00 & 2,00 & 1,17 & 1,07 & 0,26 \\
\hline 200 & 26,63 & 16,20 & 4,57 & 1,90 & 2,10 & 1,07 & 1,10 & 0,28 \\
\hline 400 & 27,93 & 16,75 & 5,00 & 2,10 & 2,00 & 1,27 & 1,11 & 0,24 \\
\hline Média & 26,14 & 15,81 & 4,70 & 1,98 & 1,96 & 1,21 & 1,06 & 0,26 \\
\hline
\end{tabular}

sível que um maior teor de umidade nos frutos favoreça a proliferação dos microrganismos, que, segundo Leite (1991), em qualquer condição adversa aos grãos, a enzima polifenoloxidase atua sobre os compostos fenólicos, diminuindo sua ação antioxidante sobre os aldeídos, facilitando, conseqüentemente, a oxidação dos mesmos. Nesta situação, produzem-se quinonas, as quais agem como inibidoras da ação da enzima.

Também a ação dos microorganismos sobre os frutos proporciona uma redução dos açúcares não-redutores e totais, que são usados para o seu desenvolvimento, e um aumento dos açúcares redutores nos grãos de café (Leite, 1991). Esta tendência verifica-se na fonte $\mathrm{KCl}$, na qual ocorre uma redução dos açúcares não-redutores e totais nos grãos beneficiados (Fig. 1) e um maior teor de açúcares redutores (Tabela 2), o que mostra uma ação indireta do ânion $\mathrm{Cl}^{-}$sobre esta variável, sendo observada ainda uma correlação negativa com $\mathrm{Cl}^{-}$nas folhas (Tabela 3 ).
Observa-se, na Fig. 1, que os açúcares não-redutores e totais apresentaram uma resposta quadrática dentro do $\mathrm{K}_{2} \mathrm{SO}_{4}$. Verifica-se uma correlação positiva dos açúcares não-redutores e totais com os teores de K e S nas folhas e nos grãos (Tabela 3), os quais tiveram um aumento com o incremento das doses de $\mathrm{K}_{2} \mathrm{SO}_{4}$. Estas correlações positivas referentes ao $\mathrm{K}_{2} \mathrm{SO}_{4}$ em relação às outras fontes demonstram uma resposta destes açúcares. O K é importante no transporte de carboidratos e ativador de enzimas em diversos processos de síntese (Malavolta, 1980; Mengel \& Kirkby, 1987) e o S tem uma influência na síntese de açúcares (Mengel \& Kirkby, 1987).

\section{CONCLUSÕES}

1. Não existe resposta de produção às fontes e doses de $\mathrm{K}$ em nenhum dos dois anos estudados.

2. A fonte sulfato de potássio promove uma melhor qualidade do café. 


\section{REFERÊNCIAS}

AMORIM, H.V.; LEGENDRE, M.G.; AMORIM, V.L.; ANGELO, A.J.S.; ORY, R.L. Chemistry of Brazilian green coffee and the quality of the beverage. VII. Total carbanyls, activity of polyphenol oxidase, and hydroperoxides. Turrialba, San José, v.26, n.2, p.193-195, 1976.

AMORIM, H.V.; SCOTON, L.C.; CASTILHO, A.; GOMES, F.P.; MALAVOLTA, E. Estudos sobre a alimentação mineral do cafeeiro. XVII. Efeito da adubação NPK na composição química do solo, do fruto e na qualidade da bebida. Anais da Escola Superior de Agricultura "Luiz de Queiroz", Piracicaba, v.22, p.139-152, 1965.

AMORIM, H.V.; SCOTON, L.C.; CASTILHO, A.; GOMES, F.P.; MALAVOLTA, E. Estudo sobre a alimentação mineral do cafeeiro. XXI. Efeito da adubação N, P e K e orgânica na composição mineral do grão e na qualidade da bebida. Anais da Escola Superior de Agricultura "Luiz de Queiroz", Piracicaba, v.24, p.215-227, 1967.

AMORIM, H.V.; SILVA, D.M. Relationship between the polyphenol oxidase activity of coffee beans and quality of the beverage. Nature, New York, v.219, n.27, p.381-382, July 1968.

AMORIM, H.V.; TEIXEIRA, A.A.; BREVIGLIER, O.; CRUZ, V.F.; MALAVOLTA, E. Chemistry of Brasilian green coffee on the quality of the beverage. I.Carbohydrates. Turrialba, San José, v.24, n.2, p.214-216, 1974.

AMORIM, H.V.; TEIXEIRA, A.A.; MORAES, R.S.; REIS, A.J.; GOMES, F.P.; MALAVOLTA, E. Estudos sobre alimentação mineral do cafeeiro. XXVII. Efeito da adubação N, P e K no teor de macro e micro nutrientes do fruto e na qualidade da bebida do café. Anais da Escola Superior de Agricultura "Luiz de Queiroz", Piracicaba, v.30, p.323-333, 1973.

ARCILA-PULGARIN, J.; VALÊNCIA-ARISTIZÁBAL, G. Relación entre la actividad de la polifenoloxidase (PFO) y las pruebas de catación como medidas de la calidad de la bebida del café. Cenicafé, Chinchiná, v.26, p.55-71, abr.jun. 1975.

ASSOCIATION OF OFFICIAL ANALYTICAL CHEMISTS. Official methods of analysis of the Association of Official Analytical Chemists. 11.ed. Washington, 1970. 1015p.
CARVAlHO, V.D. de; CHAGAS, S.J. de R.; CHALFOUN, S.M.; BOTREL, N.; JUSTE JUNIOR, E.S.G. Relação entre a composição físicoquímica e química do grão beneficiado e a qualidade de bebida do café. I. Atividades de polifenoloxidase e peroxidase, índice de coloração de acidez. Pesquisa Agropecuária Brasileira, Brasília, v.29, n.3, p.449454, mar. 1994.

CHAGAS, S.J.R. Caracterização química e qualitativa de cafés de alguns municípios de três regiões produtoras de Minas Gerais. Lavras: ESAL, 1994. 95p. Dissertação de Mestrado.

COMISSÃO DE FERTILIDADE DO SOLO DO ESTADO DE MINAS GERAIS. Recomendação para uso de corretivos e fertilizantes em Minas Gerais. Lavras, 1989. 159p.

FELDMAN, J.R.; RYDER, W.S.; KUNG, J.T. Importance of non volatile compounds to the flavor of coffee. Journal of Agriculture and Food Chemistry, Washington, v.17, p.733-739, 1969.

GOUNY, P. Observaciones sobre el comportamiento del vegetal en presencia de ions de cloro. Revista de la Potassa, Berna, v.45, n.5, p.1-14, 1973.

GUIMARÃES, P.T.G. Respostas do cafeeiro (Coffea arabica L. cv. Catuaí) à adubação mineral e orgânica em solos de baixa fertilidade do Sul de Minas Gerais. Piracicaba: ESALQ, 1986. 140p. Tese de Doutorado.

HIROCE, R.; BATAGLIA, O.C.; MORAES, F.R.P.; GALLO, J.R.; NERY, C.; LAUN, C.R.P. Relações entre os teores de macronutrientes, boro e zinco das folhas de cafeeiro e as produções. Ciência e Cultura, São Paulo, v.27, n.4, p.390-399, 1975.

LACROIX, R.L.; KEENEY, D.R.; WALSH, L.M. Potenciometric titration of chloride in plant tissue extracts using the chlorine in electrode. Communications in Soil Science and Plant Analysis, Madison, v.1, n.1, p.1-6, Jan. 1970.

LEITE, I.P. Influência do local de cultivo e do tipo de colheita nas características físicas, composição química do grão e qualidade do café (Coffea arabica, L.). Lavras: ESAL, 1991. 131p. Dissertação de Mestrado.

LOCKHART, E.E. Chemistry of coffee. New York: The Coffee Brewing Institute, 1957. 20p. (Publication, 25). 
MALAVOLTA, E. Elementos de nutrição mineral de plantas. São Paulo: Agronômica Ceres, 1980. 251p.

MALAVOLTA, E. Nutrição, adubação e calagem para cafeeiro. In: RENA, A.B.; MALAVOLTA, E.; ROCHA, M.; YAMADA, T. (Eds.). Cultura do cafeeiro: fatores que afetam a produtividade. Piracicaba: POTAFOS, 1986. p.165-275.

MALAVOLTA, E. Nutrição mineral e adubação do cafeeiro: colheitas econômicas máximas. São Paulo: Agronômica Ceres, 1993.210p.

MALAVOLTA, E.; VITTI, G.C.; OLIVEIRA, S.A. Avaliação do estado nutricional das plantas. Piracicaba: POTAFOS, 1989. 201p.

MARTINS, M.; GARCIA, A.W.D.; FIORANTE, N. Estudo de fontes de potássio para o cafeeiro. In: CONGRESSO BRASILEIRO DE PESQUISAS CAFEEIRAS, 9., 1981, São Lourenço. Anais... São Lourenço: IBC/GERCA, 1981. p.247-249.

MENGEL, K.; KIRKBY, E.A. Principales of plant nutrition. 4.ed. Berna: International Potash Institute, 1987. $687 \mathrm{p}$.

NAVELLIER, P. Coffe. In: ENCYCLOPEDIA of Industrial Chemical Analysis. New York: John Wiley \& Sons, 1970. v.19, p.373-447.

NELSON, N. A photometric adaptation of somogy method for the determination of glucose. Journal of
Biological Chemists, Baltimore, v.153, n.1, p.370380, 1944.

PAVAN, M.A.; CHAVES, J.C.P.; MESQUITA FILHO, L. Manejo da adubação para formação de lavouras cafeeiras. Pesquisa Agropecuária Brasileira, Brasília, v.21, n.1, p.33-42, jan. 1986.

PONTING, J.D.; JOSLYNG, M.A. Ascorbic acid oxidation and browning in apple tissue extracts. Archives of Biochemistry, New York, v.19, p.4763, 1948.

RAIJ, B. van; QUAGGIO, J.A.; CANTARELLA, H.; FERREIRA, M.E.; LOPES, A.S.; BATAGLIA, O.C. Analíse química do solo para fins de fertilidade. Campinas: Fund. Cargill, 1987. 170p.

ROBINSON, D.S.; ESKIN, N.A.M. Oxidative enzymes in foods. New York: Elsevier Applied Science, 1991. $314 p$.

SINGLETON, V.L. The total phenolic content of grapes berries during the maturation of several varieties. American Journal of Enology and Viticulture, v.17, p.126-134, 1966.

WOLFROM, M.L.; PLUNKERT, R.A.; LAVER, M.L. Carbohydrates of the coffe bean. Journal of Agricultural and Food Chemistry, Washington, v.8, n.1, p.58-65, 1960. 